\title{
Direct and Rapid Detection of Mycoplasma bovis in Bovine Milk Samples by Recombinase Polymerase Amplification Assays
}

\author{
Ruiwen $\mathrm{Li}^{1+}$, Jinfeng Wang ${ }^{2 \dagger}$, Xiaoxia Sun ${ }^{2}$, Libing $\mathrm{Liu}^{2}$, Jianchang Wang ${ }^{2 *}$ \\ and Wanzhe Yuan ${ }^{1 *}$ \\ ${ }^{1}$ College of Veterinary Medicine, Hebei Agricultural University, Baoding, China, ${ }^{2}$ Food Microbiology and Animal Quarantine \\ Laboratory, Technology Center of Shijiazhuang Customs District, Shijiazhuang, China
}

OPEN ACCESS

Edited by:

Hongchao Gou,

Guangdong Academy of Agricultural

Sciences, China

Reviewed by:

Baozheng Luo,

Technology Center of Gongbei

Customs District, China

Jun Zhao,

Henan Agricultural University, China

*Correspondence:

Wanzhe Yuan

yuanwanzhe2015@126.com

Jianchang Wang

jianchangwang1225@126.com

${ }^{+}$These authors have contributed equally to this work

Specialty section:

This article was submitted to

Clinical Microbiology,

a section of the journal

Frontiers in Cellular and

Infection Microbiology

Received: 08 December 2020

Accepted: 19 January 2021

Published: 25 February 2021

Citation:

Li R, Wang J, Sun X, Liu L, Wang J and Yuan W (2021) Direct and Rapid

Detection of Mycoplasma bovis in Bovine Milk Samples by Recombinase

Polymerase Amplification Assays.

Front. Cell. Infect. Microbiol. 11:639083.

doi: 10.3389/fcimb.2021.639083
This study aimed to detetct Mycoplasma bovis (M. bovis) in bovine milk quickly and directly by developing and validating isothermal recombinase polymerase amplification (RPA) assays. Targeting the uvrC gene of $M$. bovis, an RPA assay based on the fluorescence monitoring (real-time RPA) and an RPA assay combined with a lateral flow strip (LFS RPA) were conducted. It took $20 \mathrm{~min}$ for the real-time RPA to finish in a Genie III at $39^{\circ} \mathrm{C}$, and 15 min were required to perform the LFS RPA in an incubator block at $39^{\circ} \mathrm{C}$, followed by the visualization of the products on the lateral flow strip within $5 \mathrm{~min}$. Both of the two assays showed high specificity for $M$. bovis without any cross-reaction with the other tested pathogens. With the standard recombinant plasmid pMbovis-uvrC serving as a template, both RPA assays had a limit of detcion of $1.0 \times 10^{1}$ copies per reaction, equivalent to that of a real-time PCR assay. In the 65 milk samples collected from cattle with mastitis, the $M$. bovis genomic DNA was detected in 24 samples by both the realtime RPA and the LFS RPA assays. The developed RPA assays could detect $M$. bovis in bovine milk in an efficient, convenient, and credible manner as attractive and promising tools, and the assays would be helpful in the rapid response to $M$. bovis infection causing bovine mastitis.

Keywords: Mycoplasma bovis, uvrC gene, real-time RPA, LFS RPA, isothermal amplification

\section{INTRODUCTION}

As a major etiological agent of bovine mycoplasmosis globally, Mycoplasma bovis (M. bovis) causes various clinical symptoms in cattle, including pneumonia, arthritis, and mastitis (Nicholas and Ayling, 2003). Consequently, in addition to being recognized as a major pathogen in bovine respiratory disease complex (BRDC), M. bovis has also been found to cause cattle mastitis (Nicholas, 2011; Gioia et al., 2016). More importantly, infections with M. bovis cause considerable economic loss in the beef and dairy cattle industry, approximately 150 million euros across Europe as well as over \$100 million per year in the United States (Nicholas and Ayling, 2003). However, it is difficult for $M$. bovis to be eradicated from a farm after an outbreak, and one infected cattle could be an infection source for months or even years (Burki et al., 2015). 
As mentioned, rapid and accurate detection of $M$. bovis is imperative for effective prevention and control of the disease. Although bacteriological culture is considered to be the gold standard for the diagnosis of infection, routine diagnosis is not prioritized in practice. The culture method tends to be laborious, time-consuming, and lacks sensitivity and specificity owing to the fastidious nature of $M$. bovis, overgrowth of other contaminant bacteria, and subsequent difficulties in species identification (Khodakaram-Tafti and Lopez, 2004; Caswell and Archambault, 2007). Serological methods are typically used as a herd-level disease diagnostic test, and a variety of commercial $M$. bovis ELISA tests have been developed to detect antibodies in the milk and serum (Heller et al., 1993; Le et al., 2002; Nicholas and Ayling, 2003). However, they are not ideally suited for $M$. bovis infection investigations with individual animals, as a misdiagnosis may occur due to the delayed seroconversion after natural infection (Calcutt et al., 2018). Moreover, the high level of seroprevalence in many cattle herds restricts their routine use for diagnosis (Calcutt et al., 2018).

In efforts to avoid such disadvantages, diverse nucleic acid amplification approaches have been reported to sensitively, specifically, and immediately detect $M$. bovis from clinical samples, including milk (Clothier et al., 2010; Higa et al., 2016; Ashraf et al., 2018; Zhao et al., 2018). Dubbed the prime choice for molecular detection, PCR assays have been well established in the clinical diagnosis of cattle herds with BRDC and/or mastitis (Parker et al., 2018). However, compared with PCR assays, isothermal nucleic acid amplification assays, which are comparable to PCR and have a faster time-to-result in many cases, are more approporiate for the small-footprint devices in low-resource settings (Craw and Balachandran, 2012).

Among the recent isothermal nucleic acid amplification technologies, RPA has come into the spotlight because of its simplicity to design and optimize and its speed to obtain results. Thus, RPA technology has been widely utilized to explore different pathogens, as it tends to be fast, easy, and accurate (Piepenburg et al., 2006; Daher et al., 2016). In this paper, an exo probe-based real-time RPA and an nfo probe-based LFS RPA assays were developed and analyzed for their sensitivity and specificity for the direct detection of $M$. bovis in milk samples from cattle with mastitis.

\section{MATERIALS AND METHODS}

\section{Bacteria Strains and Clinical Samples}

M. bovis (strain PG45), Mycoplasma agalactiae (strain PG2), Mycoplasma ovipneumoniae (strain Y98), Mycoplasma hyopneumoniae (strain 168), Mycoplasma capricolum subsp. capripneumoniae (strain F38), Pasteurella multocida (strain F91G3), Staphylococcus aureus (ATCC 6538), and Pseudomonas aeruginosa (ATCC 9027) were reserved in our laboratory.

Sixty-five individual bovine milk samples were collected from eight different dairy farms in Baoding and Hengshui, Hebei Province, from July 2018 to December 2020. The samples were all gathered from cattle with mastitis.

\section{DNA Extraction}

The mycoplasma and bacterial genomic DNA were extracted with the TIANamp Bacteria DNA kit (Tiangen, Beijing, China), following the manufacturer's instructions. First, $1 \mathrm{ml}$ of each milk sample was centrifuged at $12,000 \mathrm{~g}$ for $10 \mathrm{~min}$ at $4^{\circ} \mathrm{C}$, the supernatant containing the fat and excess liquid was removed, and the pellet was washed twice with phosphate-buffered saline (PBS, pH 7.4). The washed pellet was resuspended in $200 \mu \mathrm{l}$ of PBS and then the DNA was extracted with the TIANamp Bacteria DNA kit. The extracted DNA was eluted in $50 \mu \mathrm{l}$ of nuclease-free water, and the DNA was quantified with an ND2000c spectrophotometer (NanoDrop, Wilmington, USA) and stored at $-80^{\circ} \mathrm{C}$ until use.

\section{Generation of Standard DNA}

Aimed to generate a M. bovis-standard DNA for the RPA assays, a PCR product with 1,908 bp covering the region of interest of uvrC gene, was amplified from the $M$. bovis DNA using uvrC-F and uvrC-R as primers (Table 1) and cloned into the pMD19-T (Takara, Dalian, China) for standards. The generating plasmid, pMbovis-uvrC, was transformed into Escherichia coli DH5 $\alpha$ cells and the positive clones were identified by sequencing with M13

TABLE 1 | Sequences of the primers and probes used in this study.

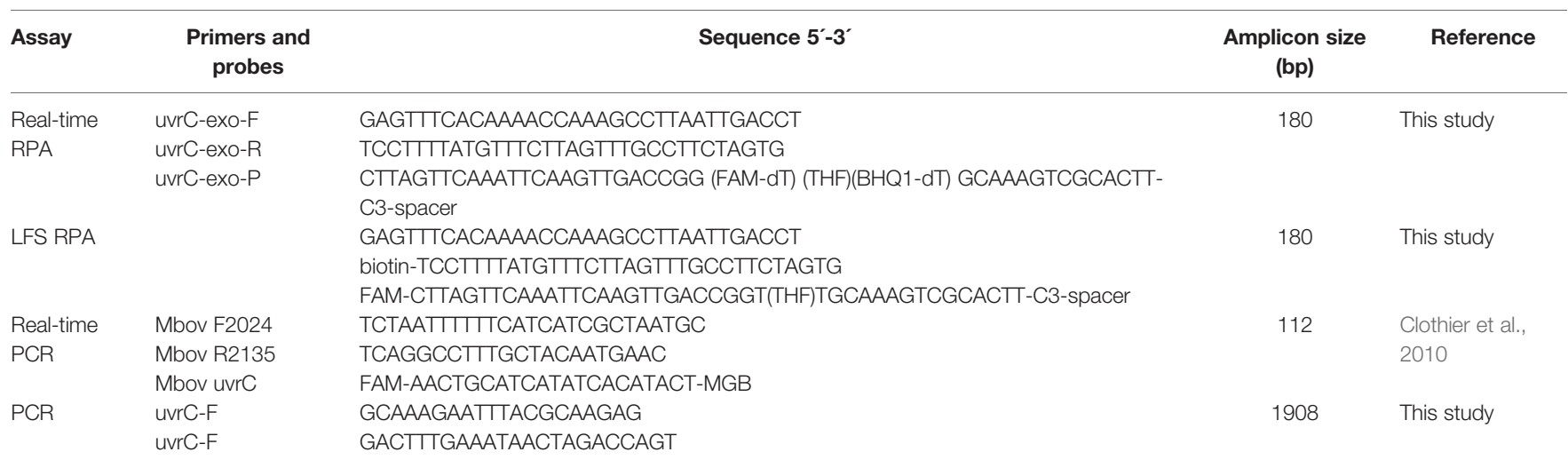


primers (Invitrogen ${ }^{\circledR}$, Carlsbad, CA, USA). pMbovis-uvrC was purified with the SanPrep Plasmid MiniPrep Kit (Sangon Biotech, Shanghai, China) and quantified with a ND-2000c spectrophotometer. The copy number of DNA molecules was calculated according to the formula as follows: amount (copies/ $\mu \mathrm{l})=[$ DNA concentration $(\mathrm{g} / \mu \mathrm{l}) /($ plasmid length in base pairs $\times$ $660)] \times 6.02 \times 10^{23}$. Aliquots of the standard DNA were prepared in 10 -fold serial dilutions from $1.0 \times 10^{7}$ to $1.0 \times 10^{0}$ copies $/ \mu \mathrm{l}$ in nuclease-free water and stored at $-80^{\circ} \mathrm{C}$ until use.

\section{RPA Primers and Probes}

Nucleotide sequence data for different $M$. bovis strains available in GenBank were aligned to identify the conserved regions in the uvrC gene, which was determined as the amplification target for RPA. Basing on the reference sequences of $M$. bovis (Acession number: AF003959, KX772801, KX772803, CP045797, KU168366, KP099619), the primers, exo probe and LF probe were designed following the RPA manufacturer guidelines (TwistDx. Cambridge, UK). Primers and probes are presented in Table 1 and were synthesized by Sangon Biotech Co., Shanghai, China.

\section{Real-Time RPA Assay}

A commercial ZC BioScience ${ }^{\mathrm{TM}}$ exo kit (ZC BioScience, Hangzhou, China) was employed in the $M$. bovis real-time RPA assay. The reaction volume was $50 \mu \mathrm{l}$ including $40.9 \mu \mathrm{l}$ of Buffer A (rehydration buffer), $2.0 \mu \mathrm{l}$ of each RPA primer (uvrC-exo-F and uvrC-exo-R, $10 \mu \mathrm{mol} / \mathrm{L}$ ), $0.6 \mu \mathrm{l}$ of exo probe (uvrC-exo-P, 10 $\mu \mathrm{mol} / \mathrm{L}$ ), and $2.5 \mu \mathrm{l}$ of Buffer B (magnesium acetate, $280 \mathrm{mmol} / \mathrm{L}$ ). Additionally, $1 \mu \mathrm{l}$ of bacterial genomic DNA or standard DNA was used for the specificity and sensitivity analysis, while $2 \mu \mathrm{l}$ of sample DNA was used for the clinical sample diagnosis. Real-time RPA reactions were performed at $39^{\circ} \mathrm{C}$ for $20 \mathrm{~min}$ in a Genie III (OptiGene Limited, West Sussex, UK).

\section{LFS RPA Assay}

A commercial TwistAmp ${ }^{\mathrm{TM}}$ nfo kit (TwistDX, Cambridge, UK) and lateral flow strip (USTAR, Hangzhou, China) were utilized in the $M$. bovis LFS RPA assay. The reaction volume was $50 \mu \mathrm{l}$ including $29.5 \mu \mathrm{l}$ of rehydration buffer, $2.1 \mu \mathrm{l}$ of each RPA primer (uvrC-nfo-F and uvrC-nfo-R, $10 \mu \mathrm{mol} / \mathrm{L}$ ), $0.6 \mu \mathrm{l}$ of exo probe (uvrC-nfo-P, $10 \mu \mathrm{mol} / \mathrm{L}$ ), and $2.5 \mu \mathrm{l}$ of magnesium acetate (280 $\mathrm{mmol} / \mathrm{L})$. In addition, $1 \mu \mathrm{l}$ of bacterial genomic DNA or standard DNA was used for the specific and sensitive analysis, while $2 \mu \mathrm{l}$ of sample DNA was used for the clinical sample diagnosis. The LFS RPA reactions were incubated in an incubator block at $39^{\circ} \mathrm{C}$ for $5,10,15$, and $20 \mathrm{~min}$. The lateral flow strips were used to recognize the amplicons dual-labeled with FAM and biotin. The LFS RPA products were identified visually by using lateral flow strips according to the manufacturer's instructions.

\section{Analytical Specificity and Sensitivity Analysis}

The specificity of the developed real-time RPA and LFS RPA assays was assessed using the genomic DNA of a panel of pathogens, including M. bovis, M. agalactiae, M. ovipneumoniae, M. hyopneumoniae, M. capricolum subsp. capripneumoniae,
P. multocida, S. aureus, and P. aeruginosa. Five of these were closely related Mycoplasma species, and the other three could potentially be associated with mastitis in cattle. The assays were conducted independently in triplicate.

Aliquots of the $M$. bovis standard DNA ranging from $1.0 \times$ $10^{7}$ to $1.0 \times 10^{0}$ copies/ $\mu$ l were used to analyze the RPA analytical sensitivity. One microliter of each dilution was amplified by both RPA assays, and the limit of detection (LOD) was determined as the highest dilution of the virus detectable by the assays. The real-time RPA was additionally tested using the standard DNA in eight replicates, the threshold time was plotted against the molecules identified, and a semilog regression was calculated by Prism software 5.0 (GraphPad Software Inc., San Diego, CA, USA). Furthermore, in the LFS RPA, three independent reactions proceeded separately.

\section{Validation With Clinical Samples}

The developed assays were directly applied to DNA extracted from 65 bovine milk samples to confirm the applicability of the M. bovis-specific real-time RPA and LFS RPA assays in clinical diagnosis,. Then, the results were compared with those obtained with real-time PCR described previously (Clothier et al., 2010), which was run in parallel for the above clinical samples.

\section{RESULTS}

\section{Performance of the Real-Time RPA Assay}

In the analytical specificity analysis, only the M. bovis DNA was amplified with the development of a typical fluorescence curve, and none of the other pathogens were amplified (Figure 1A), suggesting that the real-time RPA assay was highly specific to $M$. bovis. Similar results were observed in three repeats, demonstrating the good repeatability of the assays.

The real-time RPA assay was conducted eight times, in which $1.0 \times 10^{7}-1.0 \times 10^{1}$ copies of standard plasmid were detected in $8 / 8$ runs, and $1.0 \times 10^{0}, 0 / 8$ (Figure 1B). From these results, what have been exhibited is the LOD for the real-time RPA was $1.0 \times$ $10^{1}$ copies/reaction. Moreover, the dynamic detection range of the real-time RPA spans seven logs ranging from seven to one log copies per reaction, with the corresponding threshold time ranging from $2 \mathrm{~min}$ at $1.0 \times 10^{7}$ copies/reaction to $12 \mathrm{~min}$ at $1.0 \times 10^{1}$ copies/reaction, which revealed that the $M$. bovis realtime RPA assay has a wide dynamic range to detect the target DNA (Figure 1C).

\section{Performance of the LFS RPA Assay}

The optimal reaction time of the LFS RPA assay was evaluated by testing the results at $5,10,15$, and 20 min with $1.0 \times 10^{5}$ copies standard plasmids as the template, and the results are presented in Figure 2A. A very weak red band was observed after $5 \mathrm{~min}$ of incubation, and no distinct differences were observed among the products after 10,15, and 20 min of incubation. Similar results were obtained from three repeats. Based on the above results, 15 min was selected as the best incubation time for the M. bovis LFS RPA assay. 
A

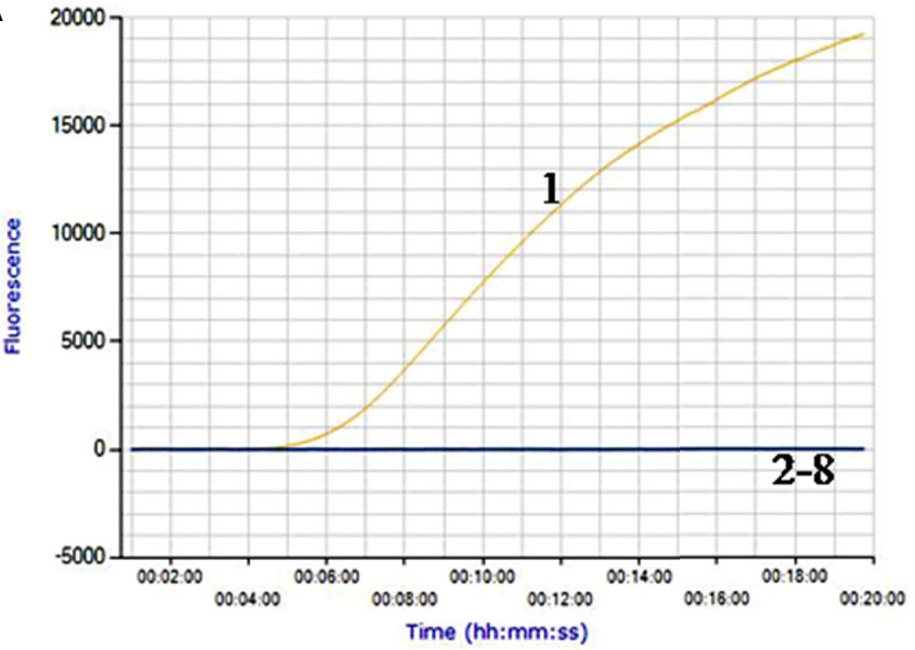

B

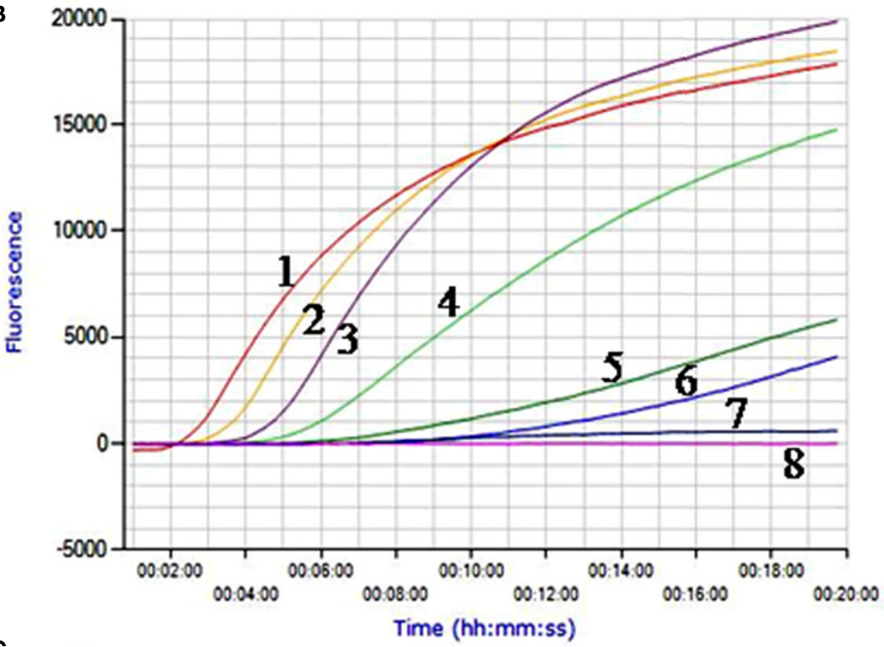

C

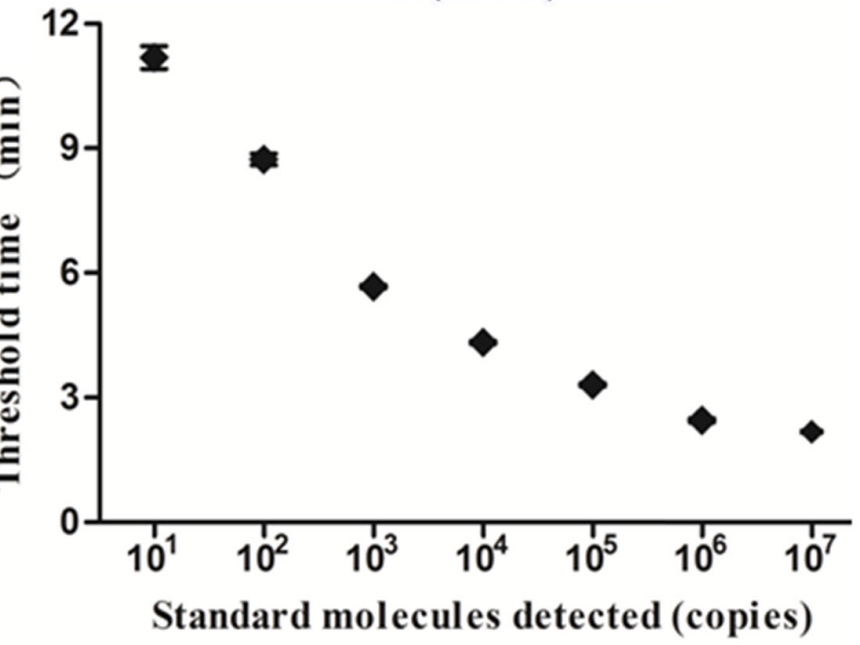

FIGURE 1 | Performance of $M$. bovis real-time RPA assay. (A) Analytical specificity of the real-time RPA assay. Only the M. bovis was amplified and there were no crossreactions with other pathogens tested. Line 1, M. bovis; line 2, M. agalactiae; line 3, M. ovipneumoniae; line 4, M. hyopneumoniae; line 5, M. capricolum subsp. capripneumoniae; line 6, P. multocida; line 7, S. aureus; line 8, P. aeruginosa. (B) Fluorescence development over time using a dilution range of $1.0 \times 10^{7}-1.0 \times 10^{\circ} \mathrm{copies} \mathrm{of} \mathrm{M}$. bovis standard recombinant plasmid. Line 1, $1.0 \times 10^{7}$ copies; line 2, $1.0 \times 10^{6}$ copies; line 3, $1.0 \times 10^{5}$ copies; line 4, $1.0 \times 10^{4}$ copies; line 5, $1.0 \times 10^{3}$ copies; line 6, $1.0 \times 10^{2}$ copies; line 7, $1.0 \times 10^{1}$ copies; line $8,1.0 \times 10^{0}$ copies. (C) Reproducibility of M. bovis real-time RPA assay. The data collected from M. bovis real-time RPA tests and the semi-log regression was calculated using Prism Software. The run time of the real-time RPA was between $2 \mathrm{~min}$ and $12 \mathrm{~min}$ for $1.0 \times 10^{7}$ and $1.0 \times 10^{1}$ copies. 


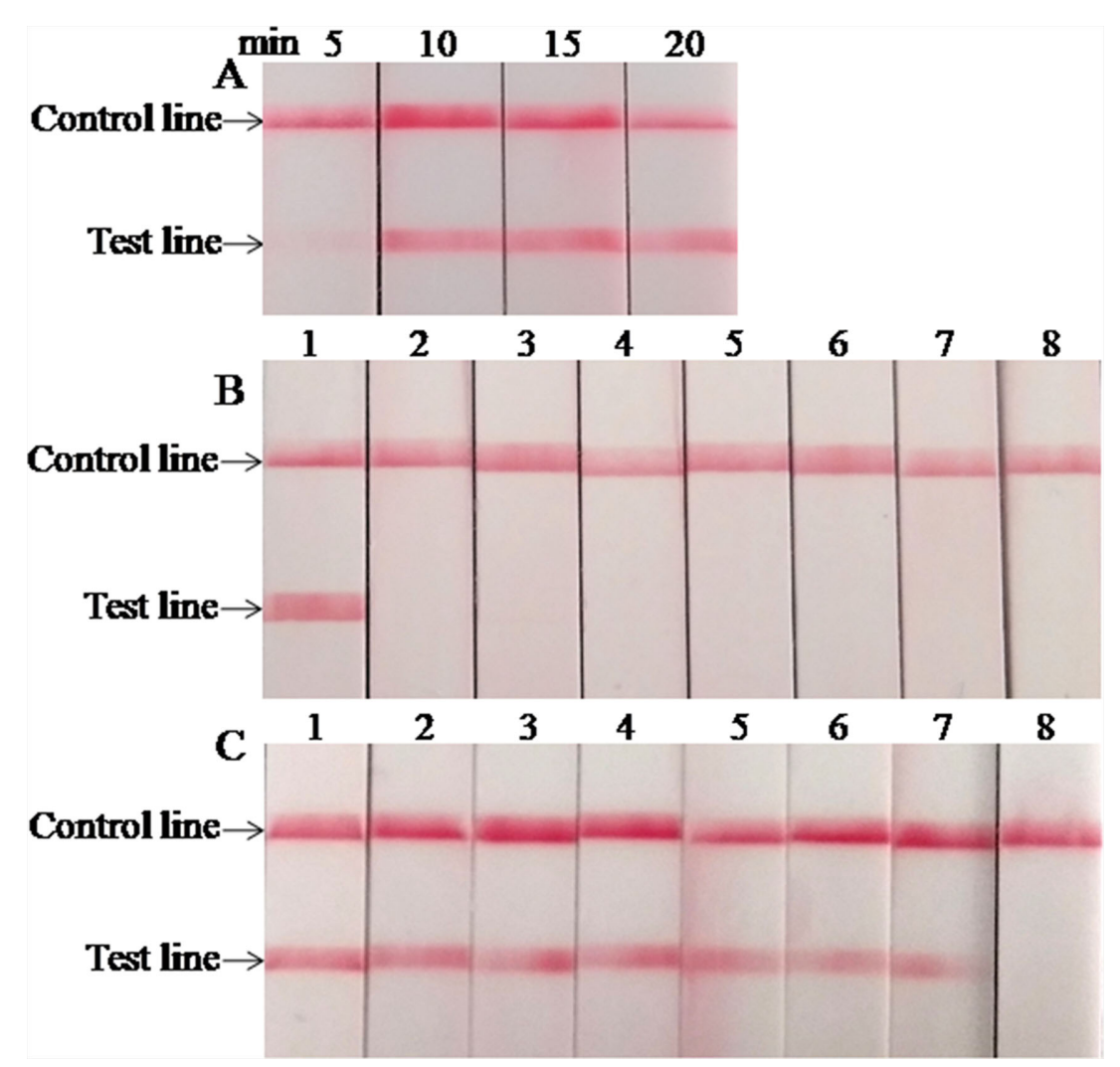

FIGURE 2 | Performance of M. bovis LFS RPA assay. (A) Optimization of LFS RPA reaction time. The test line was clearly visible when the amplification time was longer than $10 \mathrm{~min}$. (B) Analytical specificity of the LFS RPA assay. Only the M. bovis was amplified, but not other pathogens tested. Line 1, M. bovis; line 2, M. agalactiae; line 3, M. ovipneumoniae; line 4, M. hyopneumoniae; line 5, M. capricolum subsp. capripneumoniae; line 6, P. multocida; line 7, S. aureus; line 8, P. aeruginosa. (C) Analytical sensitivity of the LFS RPA assay. Line 1, $1.0 \times 10^{7}$ copies; line 2, $1.0 \times 10^{6}$ copies; line 3, $1.0 \times 10^{5}$ copies; line 4, $1.0 \times 10^{4}$ copies; line $5,1.0 \times 10^{3}$ copies; line 6, $1.0 \times 10^{2}$ copies; line 7, $1.0 \times 10^{1}$ copies; line 8, $1.0 \times 10^{0}$ copies.

When the analytical specificity analysis was conducted, the red band was only observed in the test line on the strip when the DNA of $M$. bovis was used as the template (Figure 2B), and the same results were seen in three independent reactions that the same results were received. As mentioned above, these results revealed that the LFS RPA assay was highly specific for detecting $M$. bovis and showed no cross-reactions with the other pathogens tested. As the analytical sensitivity analysis proceeded, red bands could be observed in the test line on the strips with $1.0 \times 10^{7}-1.0 \times 10^{1}$ copies of standard plasmid serving as the template (Figure 2C), and all three independent reactions showed identical results. Thus, the LOD of the LFS RPA was $1.0 \times 10^{1}$ copies/reaction.

\section{Validation of the RPA Assays on Clinical Samples}

The real-time RPA, LFS RPA, and real-time PCR all had identical results for the 65 milk samples from eight farms, in which 24 samples from four farms tested positive for M. bovis (Table 2). Using the real-time PCR as the reference, the diagnostic specificity (DSp) and diagnostic sensitivity (DSe) of the realtime RPA and LFS RPA assays were 100\%. The threshold time
(TT) and cycle threshold (Ct) values of the real-time RPA and real-time PCR were good at an $\mathrm{R}^{2}$ value of 0.951 (Figure 3).

\section{DISCUSSION}

M. bovis is the most prevalent agent of mycoplasma mastitis in dairy cattle (Gioia et al., 2016). It can survive in the milk of asymptomatically infected and clinically healthy cows, and ingestion of milk from cows with mastitis is one of the primary modes of transmission (Maunsell et al., 2011). Both bovine individual and bulk tank milk samples have been applied to recognize $M$. bovis in daily surveillance and eradication efforts (Passchyn et al., 2012; Pinho et al., 2013). Concerning the uvrC gene, this paper proposed and demonstrated that real-time RPA and LFS RPA assays could directly identify $M$. bovis in milk samples, and the tests were proven to be rapid, sensitive, and specific.

Selecting the target gene is critical for the application of nucleic acid amplification. A series of PCR and LAMP assays targeting various genes, such as $u v r C$, oppD/F, polC, gyrB, and $16 S$ rRNA, have been conducted for the species-specific detection of $M$. bovis in diverse clinical samples from cattle herds with 
TABLE 2 | Detection results of M. bovis in milk samples from cattle with mastitis in the developed real-time RPA, LFS RPA, and real-time PCR assays.

\begin{tabular}{|c|c|c|c|c|c|c|c|c|}
\hline \multirow[t]{2}{*}{ Origin } & \multirow[t]{2}{*}{ Location } & \multirow[t]{2}{*}{ Number } & \multicolumn{2}{|c|}{ Real-time RPA } & \multicolumn{2}{|c|}{ LFS RPA } & \multicolumn{2}{|c|}{ Real-time PCR } \\
\hline & & & $\mathbf{P}$ & $\mathbf{N}$ & $\mathbf{P}$ & $\mathbf{N}$ & $\mathbf{P}$ & $\mathbf{N}$ \\
\hline Farm 1 & Baoding & 17 & 10 & 7 & 10 & 7 & 10 & 7 \\
\hline Farm 2 & Baoding & 2 & 2 & 0 & 2 & 0 & 2 & 0 \\
\hline Farm 3 & Baoding & 11 & 5 & 6 & 5 & 6 & 5 & 6 \\
\hline Farm 4 & Baoding & 6 & 0 & 6 & 0 & 6 & 0 & 6 \\
\hline Farm 5 & Hengshui & 2 & 0 & 2 & 0 & 2 & 0 & 2 \\
\hline Farm 6 & Hengshui & 7 & 0 & 7 & 0 & 7 & 0 & 7 \\
\hline Farm 7 & Hengshui & 11 & 7 & 4 & 7 & 4 & 7 & 4 \\
\hline \multirow[t]{2}{*}{ Farm 8} & Hengshui & 9 & 0 & 9 & 0 & 9 & 0 & 9 \\
\hline & $\mathrm{T}$ & 65 & 24 & 41 & 24 & 41 & 24 & 41 \\
\hline
\end{tabular}

$P$, positive; $N$, negative; $T$, total.

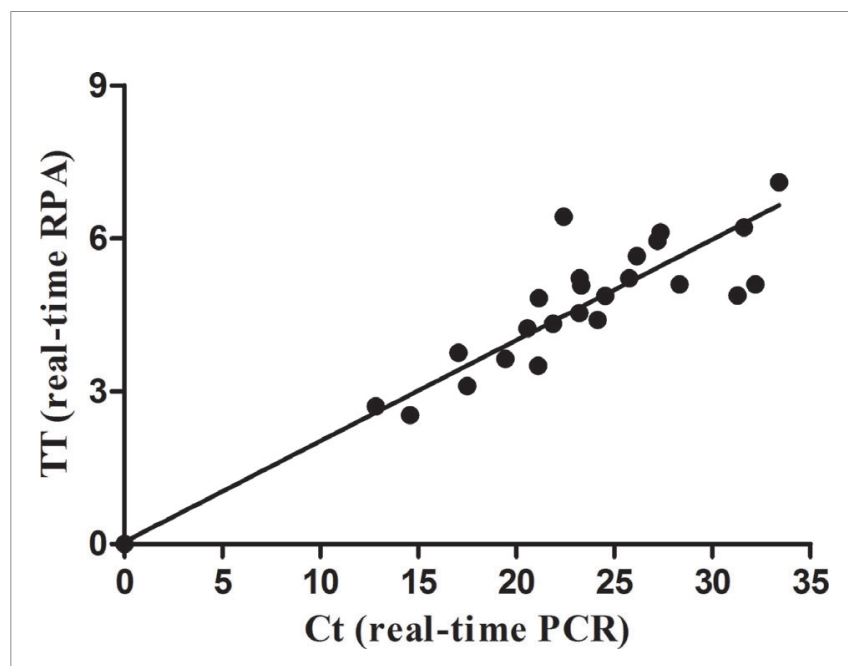

FIGURE 3 | Comparison between performances of the real-time RPA and real-time PCR on the milk samples. DNA extracts of the positive milk samples were screened. Linear regression analysis of real-time RPA threshold time (TT) values (y axis) and real-time PCR cycle threshold (Ct) values (x axis) were determined by Prism software, and the $R^{2}$ value was 0.951 .

BRDC and/or mastitis (Clothier et al., 2010; Rossetti et al., 2010; Ashraf et al., 2018). A study indicated that most PCR assays targeting different genes performed comparatively (Wisselink et al., 2019). Nevertheless, all the sequences of the 16S rRNA genes of $M$. bovis and $M$. agalactiae are extremely similar (>99.8\%) (Pettersson et al., 1996; Konigsson et al., 2002), the available $M$. bovis PCR and LAMP assays targeting the $16 S$ rRNA gene exhibited cross-reactivity with $M$. agalactiae (Ashraf et al., 2018; Wisselink et al., 2019). The uvrC gene is a highly conserved housekeeping gene specific for each of Mycoplasma species that is highly stable within a species, and it differs considerably between the two phylogenetically closely related Mycoplasma species, M. bovis and M. agalactiae (Subramaniam et al., 1998; Konigsson et al., 2002). Several previous studies have revealed that the uvrC gene is universally deemed to be the preferred target for $M$. bovis in the nucleic acid amplification assays (Clothier et al., 2010; Ashraf et al., 2018; Zhao et al., 2018; Wisselink et al., 2019). As a result, the M. bovis RPA primers and probes were designed to target the conserved region of the $u v r C$ gene in this study. Through in silico analysis, there was no mismatch in the primers and probes with the currently circulating strains available in GenBank. For the specificity analysis, both the real-time RPA and the LFS RPA could only amplify the genomic DNA of $M$. bovis but not the other mycoplasmas, including $M$. agalactiae. With the recombinant plasmid being the standard, the LOD of both RPA assays was $1.0 \times 10^{1}$ copies per reaction. Unfortunately, only one M. bovis strain and one $M$. agalactiae stain were considered in the analysis, which may be a shortcoming of this study. The developed assays should be further confirmed by testing more M. bovis and M. agalactiae DNA extracts in the future.

Directly detecting $M$. bovis in milk samples has the potential to be of great significance for the control of $M$. bovis-causing bovine mastitis. Fortunately, the developed real-time RPA and LFS RPA assays could detect the M. bovis in a direct and efficient way from clinical bovine milk samples. In this study, the M. bovis positive rate at the farm level and at the individual level reached $50.0 \%$ $(4 / 8)$ and $36.92 \%$ (24/65), respectively. Compared with a real-time PCR assay, the real-time RPA and LFS RPA assays showed DSp and Dse values of $100 \%$. The RPA assays showed positive results within $20 \mathrm{~min}$, demonstrating $\mathrm{Ct}$ values varying from 12.83 to 33.40 for the real-time PCR. The diagnostic performances of the developed RPA assays were the same as that of the real-time PCR assay, while the RPA assays demonstrated two distinct merits, rapidness and convenience. Although the above results are inspiring, RPA assays still require further validation by testing additional types of $M$. bovis DNA-positive clinical samples, such as nasal swabs and lungs. Overall, our results demonstrated that the performance of the RPA assays was comparable to that of realtime PCR, but the RPA assays were relatively faster.

Considered the prime assay in the realm of molecular detection, the PCR assays are, however, limited in underequipped laboratories and at point-of-need (PON) diagnosis owing to the demands of expensive thermocyclers and centralized laboratory facilities (Clothier et al., 2010; Rossetti et al., 2010). The recently developed LAMP assays do not require a specialized instrument, but the reaction time is 60 or 120 min (Higa et al., 2016; Ashraf et al., 2018). In this study, the developed real-time RPA assay and LFS RPA assay were performed on the portable tube scanner Genie III and in a metal bath incubator, respectively. Both of these devices are portable and can be charged by a battery, allowing 
them to work for an entire day with no need for an electrical outlet. Combined with the time needed for DNA extraction, the developed RPA assays require less than 50 min to obtain results. Moreover, RPA reagents are cold chain independent and RPA is tolerant to common PCR inhibitors (Daher et al., 2016; Lillis et al., 2016). These advantages make the developed RPA assays perfect for detecting M. bovis in the field.

Similar to the PCR and LAMP assays, DNA extraction by commercial nucleic acid extraction kits is still necessary for the RPA assays developed in this study. Currently, numerous simple and rapid nucleic acid extraction methods that do not require complex instruments are being evaluated in our laboratory, including the innuPREP MP basic kit A (Jena Analytik, Jena, Germany), Punch-it ${ }^{\mathrm{TM}}$ NA-Sample Kit (NanoHelix, Daejeon, South Korea), and other commercial reagents. Combining the DNA extracted by those simple methods with comparable performance to routine commercial nucleic acid extraction kits has the potential to allow the recentlyl developed RPA assays for $M$. bovis to be applied in the field.

In summary, the developed $M$. bovis real-time RPA and LFS RPA assays could be performed in the laboratory as routine diagnostic assays, and they have substantial potential as uncomplicated, rapid, and reliable methods for directly detecting $M$. bovis in bovine milk on farm.

\section{REFERENCES}

Ashraf, A., Imran, M., Yaqub, T., Tayyab, M., Shehzad, W., Mingala, C. N., et al. (2018). Development and validation of a loop-mediated isothermal amplification assay for the detection of Mycoplasma bovis in mastitic milk. Folia Microbiol. (Praha) 63, 373-380. doi: 10.1007/s12223-017-0576-x

Burki, S., Frey, J., and Pilo, P. (2015). Virulence, persistence and dissemination of Mycoplasma bovis. Vet. Microbiol. 179, 15-22. doi: 10.1016/j.vetmic.2015. 02.024

Calcutt, M. J., Lysnyansky, I., Sachse, K., Fox, L. K., Nicholas, R. A. J., and Ayling, R. D. (2018). Gap analysis of Mycoplasma bovis disease, diagnosis and control: An aid to identify future development requirements. Transbound. Emerg. Dis. 65 (Suppl 1), 91-109. doi: 10.1111/tbed.12860

Caswell, J. L., and Archambault, M. (2007). Mycoplasma bovis pneumonia in cattle. Anim. Health Res. Rev. 8, 161-186. doi: 10.1017/S1466252307001351

Clothier, K. A., Jordan, D. M., Thompson, C. J., Kinyon, J. M., Frana, T. S., and Strait, E. L. (2010). Mycoplasma bovis real-time polymerase chain reaction assay validation and diagnostic performance. J. Vet. Diagn. Invest. 22, 956-960. doi: $10.1177 / 104063871002200618$

Craw, P., and Balachandran, W. (2012). Isothermal nucleic acid amplification technologies for point-of-care diagnostics: a critical review. Lab. Chip. 12, 2469-2486. doi: 10.1039/c2lc40100b

Daher, R. K., Stewart, G., Boissinot, M., and Bergeron, M. G. (2016). Recombinase Polymerase Amplification for Diagnostic Applications. Clin. Chem. 62, 947958. doi: 10.1373/clinchem.2015.245829

Gioia, G., Werner, B., Nydam, D. V., and Moroni, P. (2016). Validation of a mycoplasma molecular diagnostic test and distribution of mycoplasma species in bovine milk among New York State dairy farms. J. Dairy. Sci. 99, 4668-4677. doi: $10.3168 /$ jds.2015-10724

Heller, M., Berthold, E., Pfutzner, H., Leirer, R., and Sachse, K. (1993). Antigen capture ELISA using a monoclonal antibody for the detection of Mycoplasma bovis in milk. Vet. Microbiol. 37, 127-133. doi: 10.1016/0378-1135(93)90187-C

Higa, Y., Uemura, R., Yamazaki, W., Goto, S., Goto, Y., and Sueyoshi, M. (2016). An improved loop-mediated isothermal amplification assay for the detection of Mycoplasma bovis. J. Vet. Med. Sci. 78, 1343-1346. doi: 10.1292/jvms.15-0459

Khodakaram-Tafti, A., and Lopez, A. (2004). Immunohistopathological findings in the lungs of calves naturally infected with Mycoplasma bovis.

\section{DATA AVAILABILITY STATEMENT}

The original contributions presented in the study are included in the article/supplementary material. Further inquiries can be directed to the corresponding authors.

\section{AUTHOR CONTRIBUTIONS}

Among the authors, RL and JFW were responsible for sampling, sample testing, and writing the paper. XS and LL were responsible for data statistics and analysis. JCW and WY were responsible for editing the paper. All authors contributed to the article and approved the submitted version.

\section{FUNDING}

This work was supported by the Project for Key Common Technologies for High Quality Agricultural Development of Hebei Province (19226636D), the Research Programm of General Administration of Customs (2020HK170).

J. Vet. Med. A Physiol. Pathol. Clin. Med. 51, 10-14. doi: 10.1111/j.14390442.2004.00596.x

Konigsson, M. H., Bolske, G., and Johansson, K. E. (2002). Intraspecific variation in the 16S rRNA gene sequences of Mycoplasma agalactiae and Mycoplasma bovis strains. Vet. Microbiol. 85, 209-220. doi: 10.1016/S0378-1135(01)00517-X

Le, G. D., Calavas, D., Brank, M., Citti, C., Rosengarten, R., Bezille, P., et al. (2002). Serological prevalence of Mycoplasma bovis infection in suckling beef cattle in France. Vet. Rec. 150, 268-273. doi: 10.1136/vr.150.9.268

Lillis, L., Siverson, J., Lee, A., Cantera, J., Parker, M., Piepenburg, O., et al. (2016). Factors influencing Recombinase polymerase amplification (RPA) assay outcomes at point of care. Mol. Cell Probes 30, 74-78. doi: 10.1016/ j.mcp.2016.01.009

Maunsell, F. P., Woolums, A. R., Francoz, D., Rosenbusch, R. F., Step, D. L., Wilson, D. J., et al. (2011). Mycoplasma bovis infections in cattle. J. Vet. Intern. Med. 25, 772-783. doi: 10.1111/j.1939-1676.2011.0750.x

Nicholas, R. A., and Ayling, R. D. (2003). Mycoplasma bovis: disease, diagnosis, and control. Res. Vet. Sci. 74, 105-112. doi: 10.1016/S0034-5288(02)00155-8

Nicholas, R. A. (2011). Bovine mycoplasmosis: silent and deadly. Vet. Rec. 168, 459-462. doi: 10.1136/vr.d2468

Parker, A. M., Sheehy, P. A., Hazelton, M. S., Bosward, K. L., and House, J. K. (2018). A review of mycoplasma diagnostics in cattle. J. Vet. Intern. Med. 32, 1241-1252. doi: 10.1111/jvim.15135

Passchyn, P., Piepers, S., De Meulemeester, L., Boyen, F., Haesebrouck, F., and De Vliegher, S. (2012). Between-herd prevalence of Mycoplasma bovis in bulk milk in Flanders, Belgium. Res. Vet. Sci. 92, 219-220. doi: 10.1016/ j.rvsc.2011.03.016

Pettersson, B., Uhlen, M., and Johansson, K. E. (1996). Phylogeny of some mycoplasmas from ruminants based on 16S rRNA sequences and definition of a new cluster within the hominis group. Int. J. Syst. Bacteriol. 46, 1093-1098. doi: 10.1099/00207713-46-4-1093

Piepenburg, O., Williams, C. H., Stemple, D. L., and Armes, N. A. (2006). DNA detection using recombination proteins. PLoS Biol. 4, e204. doi: 10.1371/ journal.pbio.0040204

Pinho, L., Thompson, G., Machado, M., and Carvalheira, J. (2013). Management practices associated with the bulk tank milk prevalence of Mycoplasma spp. in dairy herds in Northwestern Portugal. Prev. Vet. Med. 108, 21-27. doi: 10.1016/ j.prevetmed.2012.07.001 
Rossetti, B. C., Frey, J., and Pilo, P. (2010). Direct detection of Mycoplasma bovis in milk and tissue samples by real-time PCR. Mol. Cell Probes 24, 321-323. doi: 10.1016/j.mcp.2010.05.001

Subramaniam, S., Bergonier, D., Poumarat, F., Capaul, S., Schlatter, Y., Nicolet, J., et al. (1998). Species identification of Mycoplasma bovis and Mycoplasma agalactiae based on the uvrC genes by PCR. Mol. Cell Probes 12, 161-169. doi: 10.1006/mcpr.1998.0160

Wisselink, H. J., Smid, B., Plater, J., Ridley, A., Andersson, A. M., Aspan, A., et al. (2019). A European interlaboratory trial to evaluate the performance of different PCR methods for Mycoplasma bovis diagnosis. BMC Vet. Res. 15, 86. doi: 10.1186/s12917-019-1819-7

Zhao, G., Hou, P., Huan, Y., He, C., Wang, H., and He, H. (2018). Development of a recombinase polymerase amplification combined with a lateral flow dipstick assay for rapid detection of the Mycoplasma bovis. BMC Vet. Res. 14, 412. doi: 10.1186/s12917-018-1703-x

Conflict of Interest: The authors declare that the research was conducted in the absence of any commercial or financial relationships that could be construed as a potential conflict of interest.

Copyright (C) 2021 Li, Wang, Sun, Liu, Wang and Yuan. This is an open-access article distributed under the terms of the Creative Commons Attribution License (CC BY). The use, distribution or reproduction in other forums is permitted, provided the original author(s) and the copyright owner(s) are credited and that the original publication in this journal is cited, in accordance with accepted academic practice. No use, distribution or reproduction is permitted which does not comply with these terms. 